\title{
INFLUENCE OF COMMUNITY PHARMACY SPECIALIZATION ON PROFESSIONAL PHARMACEUTICAL COUNSELING SCHEME IN PHARMACIES IN POZNAN AND WARSAW (POLAND) - PILOT STUDY
}

\author{
MAGDALENA WASZYK-NOWACZYK ${ }^{1 *}$, BEATA SZUKALSKA ${ }^{2}$, \\ WERONIKA GUZENDA ${ }^{3}$ and MICHAE MICHALAK ${ }^{4}$
}

\author{
'Department of Pharmaceutical Technology, Pharmacy Practice Division, \\ Poznan University of Medical Sciences, 6 Grunwaldzka Street, 60-780 Poznań, Poland \\ ${ }^{2}$ Medicover Pharmacy, 88 Baraniaka Street, 61-131 Poznań, Poland \\ ${ }^{3}$ Student's Pharmaceutical Care Group, Department of Pharmaceutical Technology, \\ Pharmacy Practice Division, Poznan University of Medical Sciences, \\ 6 Grunwaldzka Street, 60-780 Poznań, Poland \\ ${ }^{4}$ Department of Computer Science and Statistics, Poznan University of Medical Sciences, \\ 7 Rokietnicka Street, 60-806 Poznań, Poland
}

\begin{abstract}
Education of community pharmacy workers is a very important part of everyday practice, especially in professional counseling (PC) which brings many health benefits for the patients. The aim of the study was to investigate if the community pharmacy specialization has an influence on the scope and quality of counsels given by pharmacy workers during PC scheme implementation in community pharmacies. The research was carried out between May and November 2017. After PC scheme implementation in community pharmacies, an anonymous questionnaire was administered to 245 pharmacy workers in Poznan and Warsaw (241 women, 4 men): 146 pharmacists (143 women, 3 men) and 99 pharmacy technicians (98 women, 1 man). In the conducted study, $14.7 \%$ of pharmacists had community pharmacy specialization (according to Polish law). Pharmacists with a community pharmacy specialization referred patients more often to physicians $(\mathrm{p}<0.0001)$, as well as after earlier physician consultation $(\mathrm{p}<0.0001)$. Furthermore, they often noticed the interaction between drugs in patients' self-treatment and in the treatment ordered by a physician $(\mathrm{p}=0.001)$. The indication of medication contraindications after a physician consultation was also significantly higher within pharmacists with specialization $(\mathrm{p}<0.0001)$. It can be noted that pharmacists with community pharmacy specialization were asked more often for self-treatment consultation and after physician visits $(\mathrm{p}<0.0001)$. Development of PC in Polish community pharmacy, especially among pharmacy owners well-educated in community pharmacy specialization, may help to increase the safety of pharmacotherapy.
\end{abstract}

Keywords: pharmacist, community pharmacy specialization, pharmaceutical counseling, community pharmacy, pharmaceutical care

According to Polish law, every practicing pharmacist is obligated to gain 100 educational points in 5 -year periods in order to maintain the license to practice in a community pharmacy (1). Organization and subject of courses that require the scoring of points often meet with pharmacists' dissatisfaction. Nevertheless, the overwhelming majority of them declare that continuous training is essential to improve their knowledge and patient counseling (2). In order to raise their qualifications, pharmacists may also complete 3-year postgraduate specialization course that concentrates on issues concerning a selected field; e.g., community pharmacy, hospital pharmacy, clinical pharmacy, or pharmaceutical industry (3). Every course also includes an internship and ends with an exam, the positive results of which enable pharmacists to use the title of specialist in the specific area of pharmaceutical science. However, community pharmacy specialization is not obligatory even for pharmacy managers. This lack of mandate is why community pharmacists as well as their employers often don't see any possible benefits connected with this mode of qualification improvement (2). On the other hand, Polish pharma-

* Corresponding author: e-mail: mwaszyk@ump.edu.pl 
cies are undergoing changes that are essential for implementing pharmaceutical care in the future $(4,5)$.

In order to provide new health services, pharmacies will be obligated to offer proper space for consultations as well as highly qualified staff. Studies in other countries show that patients are aware of new extended roles of community pharmacies (6). This public awareness may be a signal that expectations toward pharmacists are rising. An Ethiopian survey, by contrast, revealed the main barrier to counseling type 2 diabetes patients is poor pharmacist knowledge (7). In Poland, pharmacists claim they are ready to provide professional counseling (PC) and most of them consider their knowledge sufficient $(8,9)$. Moreover, Polish and American patients in other studies confirmed that they are interested in education about prophylaxis and prevention of common chronic diseases and in health-screening services (10). Other studies that concerned implementation of pharmaceutical care for patients in Poland considered that professional pharmacy workers should educate them on dosage, side effects, preparation of medications, and drug interactions (11). It is worth mention that new services such as PC or pharmaceutical care contribute to patient satisfaction and is thus a tool for pharmacy owners to become competitive and increase financial outcome (8).

As an introduction of new services in Polish pharmacies is essential to fulfill patient needs, it is necessary to evaluate the pharmacists' preparation to the new role. The aim of the study was to investigate if the community pharmacy specialization has an influence on the scope and quality of counsels given by pharmacy workers during PC scheme implementation in community pharmacies.

\section{MATERIALS AND METHODS}

The research was carried out between May and November 2017. The study group included pharmacists and pharmacy technicians from six community pharmacies in Poznan (2) and Warsaw (4). After the training course that acquainted pharmacy workers with a standard of PC scheme, participants were asked to complete the anonymous questionnaire. It consisted of open-and-close questions which concerned information about pharmacy workers, patients, and scheme of counseling in two cases: self-treatment or after physician consultation. In this paper, we compared answers given by pharmacists with and without specialization to evaluate any significant differences between these two groups. The study was approved by the ethics review board at Poznan University of Medical Sciences.

Statistica PL 10 (StatSoft) package was used to perform the statistical analysis. The correlations between analyzed nominal data were performed by Chi-square test of independence $\left(\chi^{2}\right)$. All statistical analyses were performed at $\mathrm{p}<0.05$.

\section{RESULTS}

The questionnaire was completed by 245 professional pharmacy workers (241 women, 4 men): 146 pharmacists (143 women, 3 men) and 99 pharmacy technicians (98 women, 1 man). In Poznan, 45

Table 1. Characteristics of study participants.

\begin{tabular}{|c|c|c|c|}
\hline \multicolumn{5}{|c|}{$\begin{array}{c}\text { Professional pharmacy workers } \\
\text { n } \%\end{array}$} \\
\hline & $\begin{array}{c}\text { Pharmacists } \\
146(59.6)\end{array}$ & $\begin{array}{c}\text { Pharmacy technicians } \\
99(40.4)\end{array}$ & $\begin{array}{c}\text { Total } \\
245(100)\end{array}$ \\
\hline Gender & $3(2.1)$ & $1(1.0)$ & $4(1.6)$ \\
\hline \multicolumn{5}{|c|}{ Male } & $143(97.9)$ & $98(99.0)$ & $241(98.4)$ \\
\hline Female & $21(14.4)$ & $24(24.2)$ & $45(18.4)$ \\
\hline City & $125(85.6)$ & $75(75.8)$ & $200(81.6)$ \\
\hline \multicolumn{5}{|c|}{ Poznan } & $65(44.5)$ & $33(33.3)$ & $98(40.0)$ \\
\hline Warsaw & $15(10.3)$ & $3(3.0)$ & $18(7.4)$ \\
\hline Age [years] & $65(44.5)$ & $63(63.7)$ & $128(52.2)$ \\
\hline $24-30$ & $1(0.7)$ & $0(0.0)$ & $1(0.4)$ \\
\hline $31-40$ &
\end{tabular}




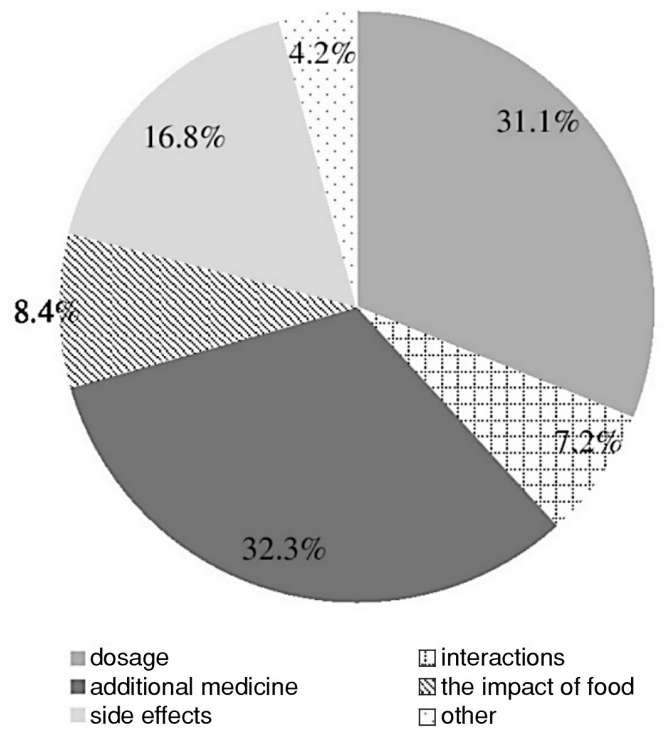

Figure 1 . The scope of community pharmacy workers advices for patients' after self-treatment $(n=343)$

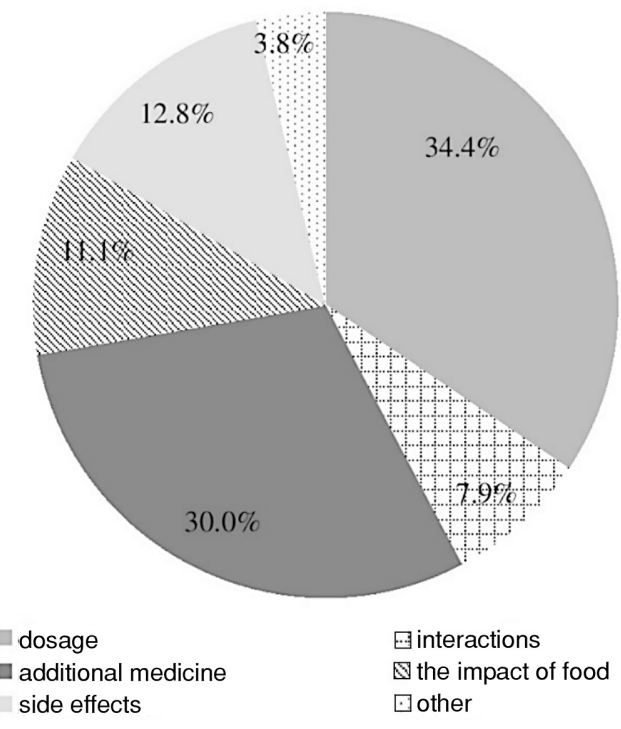

Figure 2. The scope of community pharmacy workers advices for patients' after physician consultation $(\mathrm{n}=238)$

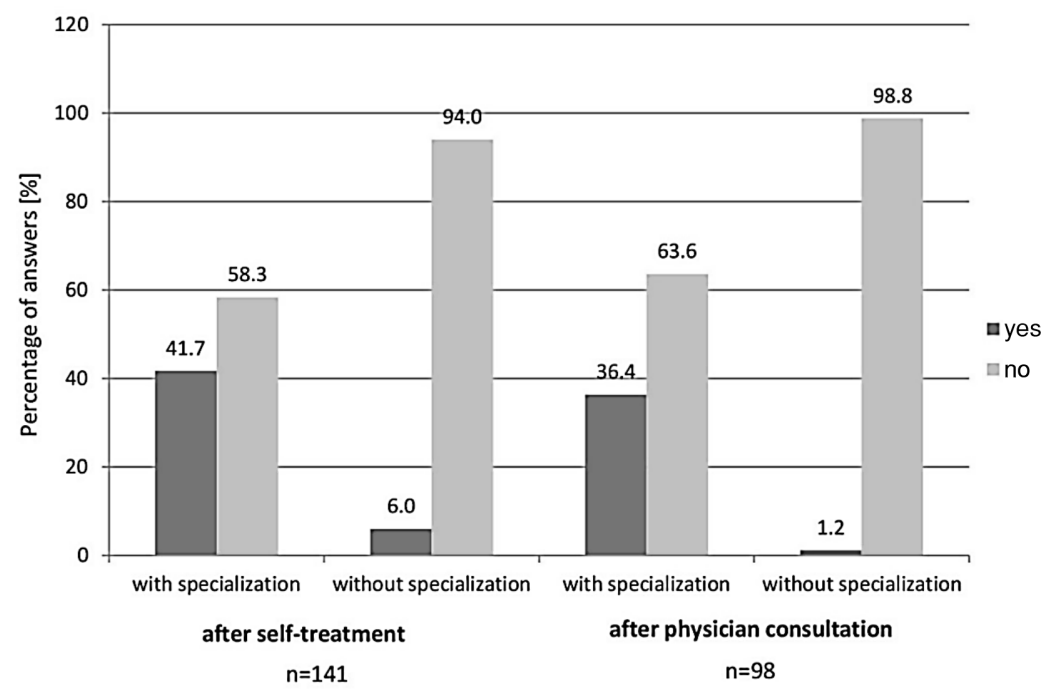

Figure 3. Patients' referring from pharmacist to physician after self-treatment and physician consultation $(\mathrm{p}<0.0001 *) ; * \mathrm{p}<0.05$

pharmacy workers were included, as well as 200 in Warsaw. They were 41 to 50 years old $(52.2 \%)$ and 24 to 30 years old $(40.0 \%)$. Characteristics of study participants are presented in Table 1.

In the conducted study, $14.7 \%$ of pharmacists had community pharmacy specialization (according to Polish law) and $85.3 \%$ had no additional skills. After self-treatment and physician consultation, the scope of advice provided by community pharmacy workers was connected mostly with dosage (respectively $34.4 \%$ and $31.1 \%$ ) and the possibility of additional medicine use (respectively $30.0 \%$ and $32.3 \%$ ). The results are presented in Figures 1 and 2. Pharmacists with community pharmacy specialization referred patients more often to physicians and also after earlier physician consultation $(\mathrm{p}<0.0001$, 
Fig. 3). Furthermore, they often noticed the interaction between drugs in patients' self-treatment and in the treatment ordered by a physician $(p=0.001$, Fig. 4$)$. The indication of medication contraindications after physician consultation was also significantly higher within pharmacists with specialization $(\mathrm{p}<0.0001$, Fig. 5). It can be noted that patients asked pharmacists with community pharmacy specialization more often for self-treatment consultation and after physician visiting (respectively $\mathrm{p}<0.0001$, Fig. 6).

\section{DISCUSSION}

Pharmacists should be perceived as pharmacology specialists especially because of their additional skills and knowledge. The role of pharmacists in community pharmacy is very meaningful, especially when they have a specialization that brings many health benefits to the patient (12). On the other hand, some surveys revealed that pharmacy workers sometimes don't have appropriate knowledge about

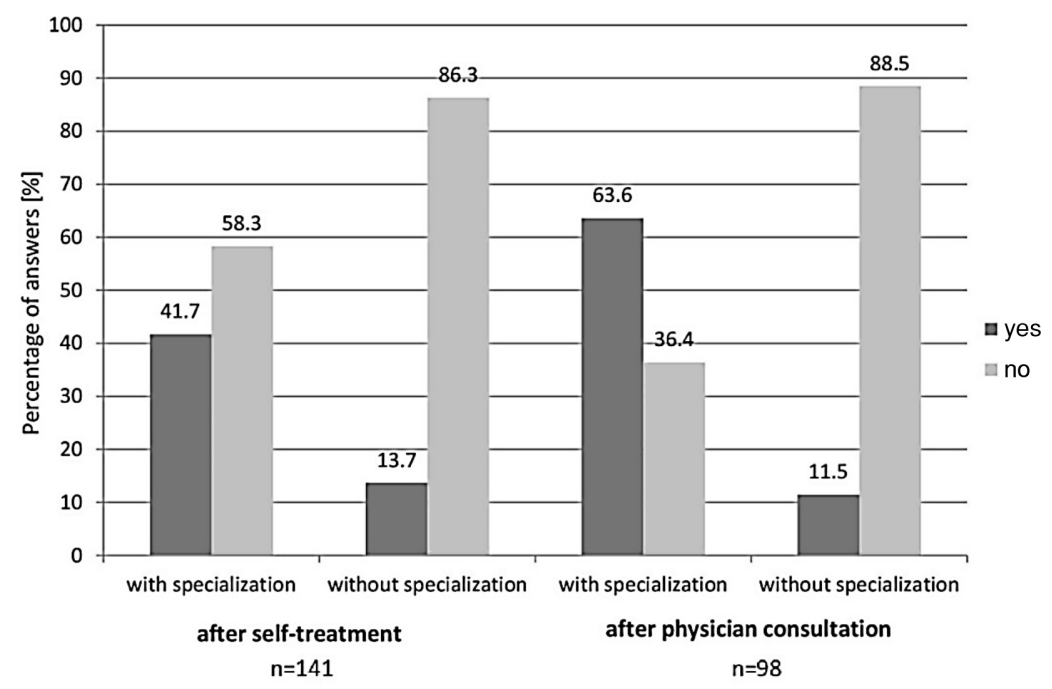

Figure 4. Pharmacists' interactions noticing after patients' self-treatment and physician consultation $(\mathrm{p}=0.001 *) ;{ }^{*} \mathrm{p}<0.05$

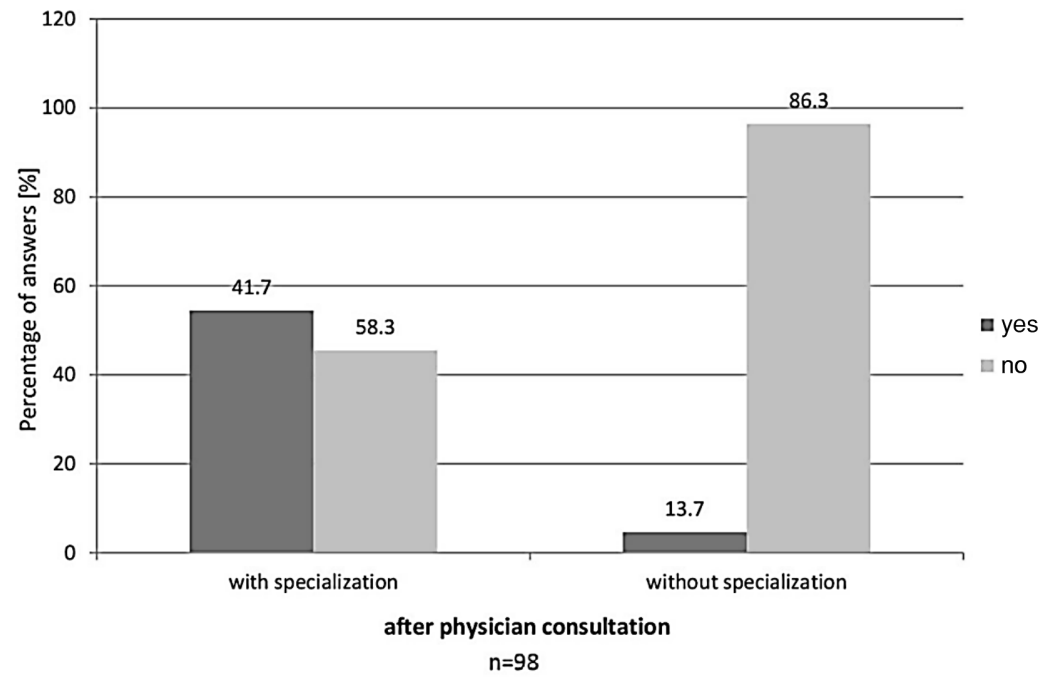

Figure 5. Pharmacists' medication contraindication noticing after physician consultation $(\mathrm{p}<0.0001 *) ;{ }^{*} \mathrm{p}<0.05$ 


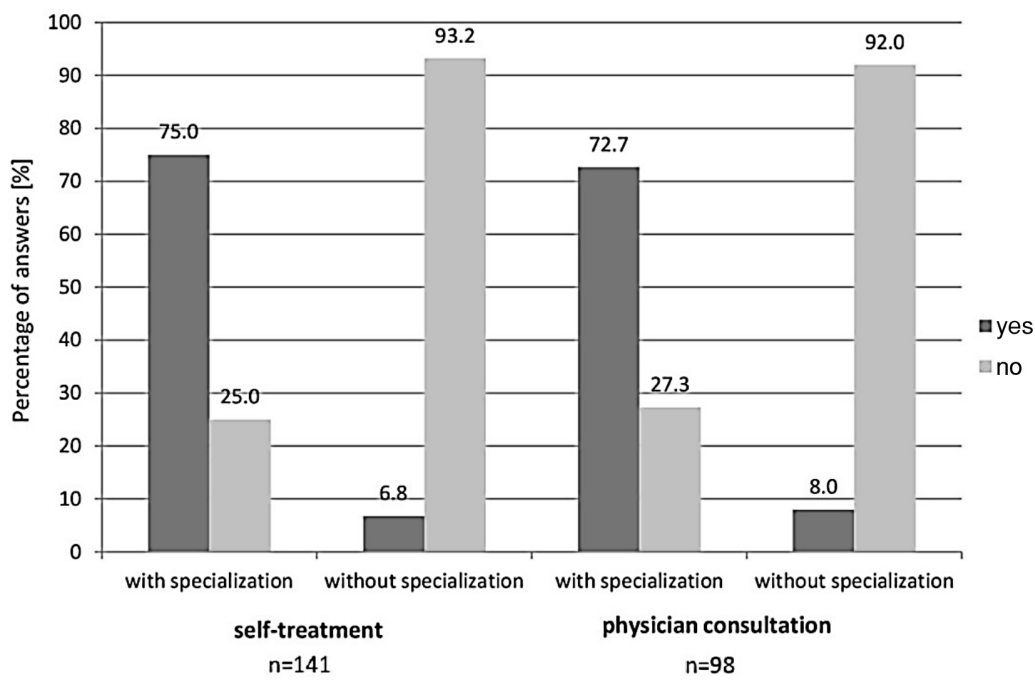

Figure 6. Patients' questions to pharmacists about self-treatment and physician consultation $(\mathrm{p}<0.0001 *) ; * \mathrm{p}<0.05$

drug safety; e.g., in terms of antibiotics and isotretinoin $(13,14)$. Pharmacists in Poland have an opportunity to be qualified specialists, especially after specific courses and trainings, but very often there are many barriers which have meaningful influence, such as lack of time or no additional gratification (9). Postgraduate courses in Poland still aren't perfect but pharmacists perceive them as a chance to improve provided services in community pharmacy. Nevertheless, they also claim that employers mostly have neutral attitudes toward pharmacy workers' training (3). This outlook is one of the barriers, alongside lack of trained staff and time to implement pharmaceutical care (15). Researches in Russia stated that not only do pharmaceutical information and counseling services need standardization but also marketing cross-selling technologies in community pharmacy must be revised (16). Our survey showed that the most common advice given by community pharmacy workers was connected to dosage and additional medicine after self-treatment or physician consultation. Thanks to the scheme of PC implemented to the selected community pharmacies, the advice given by pharmacy workers was more precise and competent. Many countries, such as Great Britain and Germany, are using procedures like SOP (Standard Operating Procedures) in daily community practice to increase the effectiveness of contact with the patient (17).

Pharmaceutical science is very broad but when it is used to provide short counsels in community pharmacy, it is necessary to select and link proper information, especially to identify interactions, con- traindications, or even drug indication and adverse reactions. A Palestinian survey showed that pharmacists demonstrated poor knowledge about food-drug interactions (18). Lack of therapeutic knowledge and access to effective drug information are the most common barriers to providing PC $(15,19)$. According to the results of our research, specialists, in significantly high number, noted interactions more frequently in self-treatment pharmacotherapy as well as in pharmacotherapy prescribed by a physician. This heightened awareness contributes to increased patient safety. As maintaining the safety of pharmacotherapy on every stage is crucial for pharmaceutical care and counseling, we may assume on this basis that only adequately educated specialists are well prepared to achieve this goal. Moreover, community pharmacy specialists oftentimes referred patients to physicians, while pharmacists without specialization seldom did. Results of our survey indicated that pharmacists with higher educational levels are more vigilant and are more likely to link facts concerning patients' health and therapy in order to intervene when a patient should consult the doctor. This vigilance is also important in providing PC and pharmaceutical care, as cooperation between representatives of medical professions (20).

To identify drug-related problems, it is essential to possess knowledge and cooperate with physicians but also to obtain patient involvement in the process. Kari et al. evaluated that during medication reviews conducted by pharmacists, $84.0 \%$ of identified drug-related problems needed patient engagement (21). Furthermore, postgraduate training help 
pharmacists interview patients in order to gain more details about their condition and it positively affects the quality of patient care and patient assessment of pharmacy workers (22). These findings are similar to ours as it occurred that pharmacists with specialization were not only giving simple counsels but also were able to get patients' attention. Patients in both cases self-treatment and after physician consultation asked more questions when they were consulted by a highly qualified pharmacy worker. This engagement is a signal that higher-educated pharmacists were more likely to get patients' attention and, as a result, to identify more significant drug problems.

Although the number of respondents was established above the minimum, authors are aware that some comparisons could not achieve the required power to detect smaller differences between groups. Nevertheless, the results have shown some trends in the analyzed population. Further investigation should be conducted to confirm these initial findings.

Community pharmacy specialization is not obligatory in Poland, but it is undeniably beneficial for patient safety and satisfaction. Thus pharmacists, by increasing their knowledge with postgraduate courses, may positively affect their own and community pharmacies' image and status. Implementation of PC in Poland gives a possibility to cooperate with a patient and physician in a better way, which can have a positive influence on patients' pharmacotherapy.

\section{Acknowledgment}

This study was supported by the funding for young scientists from Poznan University of Medical Sciences (grant no. 502-14-03314429-09415).

\section{REFERENCES}

1. http://prawo.sejm.gov.pl/isap.nsf/download. xsp/WDU20031321238/O/D20031238.pdf Government Website (accessed on 25.07.2018).

2. http://www.aptekarzpolski.pl/2018/02/oczekiwania-farmaceutow-w-zakresie-edukacji-podyplomowej-badanie-ankietowe-nia/ - Polish Pharmacist Journal, Polish Pharmaceutical Chamber (accessed on 25.07.2018).

3. https://www.cmkp.edu.pl/ksztalcenie/ksztalcenie-specjalizacyjne-farmaceutow/programyspecjalizacji-farmaceutow/ Medical Center For Postgraduate Education (accessed on 25.07. 2018).
4. Skowron A., Bulas I., Drozd M., Karolewicz B., Machalska J.: Acta Pol Pharm. 73, 255 (2016).

5. Drozd M.: Pharmaceutical care as a support for the patient in self-treatment, in Responsible and modern self-treatment in the health care system. Krajewski-Siuda K. Ed., pp.20-28, Citizens Healthfully Involved Foundation, Warsaw 2016.

6. Nunes F.G., Anderson J.E., Martins L.M.: Health Expect. 18, 2853 (2015).

7. Erku D.A., Belachew S.A., Mekuria A.B., Haile K.T., Gebresillassie B.M. et al.:Integr. Pharm. Res. Pract. 6, 137 (2017).

8. Szalonka S.: Pharmaceutical care as an innovative instrument of competing on the pharmaceutical market. Łongiewska-Wijas E. Ed., pp.91103, University of Szczecin, Szczecin 2010.

9. Waszyk-Nowaczyk M., Simon M.: Farm. Pol. 65, 713 (2009).

10. Waszyk-Nowaczyk M., Luczak A., Michalak D., Kaczmarczyk J., Myrda H. et al.: Acta Pol. Pharm. 74, 1613 (2017).

11. Cerbin-Koczorowska M., Waszyk-Nowaczyk M., Odor K., Michalak M., Piotrowska S. et al.: Farmacia 65, 159 (2017).

12. Keijsers C.J., Leendertse A.J., Faber A., Brouwers J.R., de Wildt D.J., Jansen, P.A.: J. Clin. Pharmacol. 55, 936 (2015).

13. Yakimova Y.: Int. J. Risk. Saf. Med. 27, 11 (2015).

14. Alrwisan A.A., Alshammari T.M., Tahir K.W., Aleissa F.M., Aljadhey H.S.: Saudi Med. J. 35, 81 (2014).

15. Ghazal R.M., Hassan N.A.G., Al Ahdab O.G., Saliem I.I.: IOSR J. Pharm. 5, 68 (2014).

16. Egorova S.N., Akhmetova T.: Int. J. Risk. Saf. Med. 27, 87 (2015).

17. https://www.pgeu.eu/en/press/255:pr-pgeuannual-report-2017.html (accessed on 28.04. 2018).

18. Radwan A., Sweileh A., Shraim W.: Int. J. Clin. Pharm. 40, 668 (2018).

19. Leung H.Y., Saini B., Ritchie H.E.: PLoS One 13, 0195101 (2018).

20. Waszyk-Nowaczyk M., Simon M., Szukalska B.: Medical News. 82, 262 (2013).

21. Kari H., Kortejärvi H., Airaksinen M., Laaksonen R.: Br. J. Clin. Pharmacol. doi: 10.1111/bcp.13640 (2018).

22. Liekens S., Vandael E., Roter D., Larson S., Smits T. et al.: Patient Educ. Couns. 94, 110 (2014).

Received: 2.08. 2018 